\title{
Instrumentalidad racional de la nueva economía política en la transformación institucional del estado
}

Josè G. Vargas-Hernàndez - Ph.D. Instituto Tecnológico de Cd. Guzmán - México.

\section{Resumo}

El propósito de este trabajo es analizar la racionalidad instrumental de la Nueva Economía Política en la transformación Institucional del Estado, a partir de un abordaje conceptual y metodológico transdisciplinario que implica la interacción de lo económico y lo político. La racionalidad se analiza desde sus componentes individual y social, para desprender sus implicaciones en la teoría de la acción colectiva y en la racionalidad económica de las decisiones, como elementos para determinar los diferentes enfoques de la economía política. Se hace especial énfasis en la implementación de los principios de la corriente institucionalista hasta madurar en el denominado neoinstitucionalismo y luego en una Nueva Economía Política, pasando por los fallidos intentos de la Nueva Economía y la imposición de las premisas fundamentales de la Nueva Macroeconomía Clásica en la regulación de los procesos de globalización económica. Finalmente se concluye que la Nueva Economía Política proporciona los fundamentos teóricos metodológicos y el instrumental necesario para los procesos de cambio y transformación institucional del Estado.

\section{Palavras-chave}

Instrumentalidad racional; nueva economía política; transformación institucional del Estado.

\begin{abstract}
This work objective deals with analyses the instrumental rationality of the New Political Economics in the transformation State Institutional concerning a conceptual and methodological transdisciplinary that involve the interaction of political and economics. The rationality analyses since its individual and social components to untie its implications in theory of the collective action and in economics rationality of the decisions, as elements for determine the different political economics focus. Special emphasis concerning the implementation of the institutionalism current principles until mature in the denominated neo institutionalism and just a New Political Economics passing by the tentative failure and imposition of the fundamental premises the New Classic Macroeconomic in the process regulations of the economics globalization. At last, it has been concluded that the New Political Economics proportionate the theoricalmethodological fundaments and the needed instruments for the processes of the Institutional State change and transformation.
\end{abstract}

\section{Keywords}

Instrumentality rational; new political economy; institutional transformation of the state. 


\section{ECONOMÍA POLÍTICA}

Para el estudio de los cambios en la economía global y sus consecuencias, de acuerdo con Appelbaum y Henderson (1995), se requiere un abordaje conceptual y metodológico transdisciplinario que vayan más allá de las especializaciones intelectuales, tales como la economía de los negocios, la economía política, la sociología organizacional, la geografía económica, las relaciones internacionales y los estudios del desarrollo; y que, además, permita mantener una visión plural dimensional y analógica de la realidad, de una realidad que se está convirtiendo en hiperrealidad que modifica nuestras interpretaciones fundamentadas en estructuras piramidales a estructuras de relaciones más planas.

La forma de acercarse al análisis del fenómeno del desarrollo en la era de la globalización, es a través de un enfoque que implique la interacción de lo económico y lo político. La cientificidad de una ciencia solo es cuestionable a partir de la ciencia misma, pero su modo de existir y de funcionar se cuestiona por la práctica política. La economía política intenta conectar el análisis económico con la práctica política para abordar los problemas relacionados con el desarrollo mediante el estudio de los procesos sociales institucionales de los grupos económicos y políticos y sus decisiones de elección, regulación y poder que influyen en la asignación de los recursos.

Los diferentes acercamientos a la economía política abarcan desde el que considera al individuo que actúa racionalmente como unidad de análisis hasta el enfoque de racionalidad social. La economía política racional se centra en el estudio de los intereses como productores de una dialéctica de la racionalidad e irracionalidad $y$, al considerar al individuo como la unidad de análisis, no toma en cuenta las estructuras e interacciones de los agrupamientos humanos y su influencia en el desarrollo. La cultura intelectual racionalista y científica encuentra sus limitaciones en las manifestaciones de la pluralidad.

Desde la perspectiva de la elección racional, el tema del desarrollo visto por la economía política trata de la forma en que los actores en los mercados realizan conductas estratégicas de elección y razonamiento para maximizar sus propios intereses que persiguen en función de incentivos, así como de los problemas de agregación mediante la teoría de la acción colectiva y de la acción democrática. El mito de la obtención del máximo beneficio del mercado desencadena una tendencia perversa que sobrepone la utilidad económica por sobre los valores sociales, culturales y políticos.

\section{a) Enfoque racionalista - individualista}

La elección racional (rational choice) como cuerpo teórico para explicar el comportamiento humano desplaza a los planteamientos 
basados en las normas y papeles sociales transmitidos por los mecanismos de socialización y la tradición.

El enfoque racionalista metodológicamente acepta el individualismo y se fundamenta en el principio de que los individuos (unidad de análisis) son auto interesados, orientados a la satisfacción de sus propios intereses, deseos y actividades que son determinados material y políticamente. La economía política racional se centra en el estudio de los intereses como productores de una dialéctica de la racionalidad e irracionalidad y al considerar al individuo como la unidad de análisis no toma en cuenta las estructuras e interacciones de los agrupamientos humanos y su influencia en el desarrollo.

Los individuos maximizan sus utilidades en una forma racionalmente perfecta mediante la previsión de todos los posibles resultados, la determinación de los diferentes cursos de acción y la evaluación de las consecuencias en términos de costos. Los mitos racionalizados tienen diferentes componentes de racionalidad. Los cuatro tipos de racionalidad son: la racionalidad práctica que calcula en forma pragmática los medios para sortear las dificultades, la racionalidad teórica o construcción de conceptos abstractos precisos como la deducción, atribución de causalidad, la formación de significados simbólicos, la racionalidad sustantiva o preferencia por valores últimos, y la racionalidad formal por el cálculo de medios-fines. Los conceptos de racionalidad sustantiva y de racionalidad práctica informados por las obligaciones sociales y morales son posibles rutas a incorporar el concepto de valores.

Los tipos de racionalidad que informan la acción racional son la racionalidad sustantiva que informa la acción valoración-racional y la racionalidad formal que informa la acción racional instrumental. Los tipos de acción social de Weber son el afectivo basado en la emoción, el tradicional basado en el hábito, el valoración-racional (wertrational) basado en valores, y la racionalidad medio-fin basada en el cálculo. La acción social es racional basada en ideas y elección consciente, categorizada por Weber las racionalidades afectivas y tradicional como cerca de la frontera que denominó como acción orientada, (Weber, 1978:25) mientras que la racional valoración y la acción racional mediosfines son más reflectivas (¿reflexivas?) o autoconscientes.

La racionalidad formal informa la acción racional de medios-fines. Polanyi (1975) define la acción racional como la elección de unos medios en relación con un fin. La especificidad de la acción racional no se refiere "ni a los medios ni a los fines, sino a la relación medios -fines". La racionalidad sustantiva ordena la acción con relación al valor postulado en el pasado, presente o potencial, o agrupamiento de valores donde la conducta se evalúa por sí misma, independientemente de sus prospectos de éxito. La racionalidad teórica involucra un dominio consciente de la 
realidad a través de la construcción de conceptos abstractos precisos. La racionalidad práctica guía las acciones en rutinas diarias, provee patrones de acción para los medios de trato con las dificultades prácticas inmediatas.

Los supuestos económicos de la elección racional y las implicaciones que fluyen lógicamente de estos supuestos sugieren que es el mercado, y no la intervención del Estado, el que asegura la provisión de los términos del contracto que son socialmente eficientes y óptimos para los compradores considerados como una clase.

La elección racional es un enfoque individualista porque confunde el bienestar con las preferencias y con las elecciones. La capacidad para elegir es la base de la sociedad del consumo mediante la expresión de preferencias. Para los expresivistas, la racionalidad es una forma apropiada de expresión de actitudes y expresiones que no promueven buenos resultados. Para los teóricos de la virtud, la elección racional es la elección que una persona con ciertos rasgos del carácter, tales como el buen juicio, involucramiento emocional y otros rasgos, escogería.

Habermas $(1992,408)$ puntualiza que la teoría de la elección racional todavía se relaciona con la solución del problema Hobbesiano. Los principios que critica son la estabilidad de las preferencias y la conducta de maximización de utilidad. Las preferencias declaradas del individuo no son necesariamente las preferencias que tendrían cuando están mejor informados, lo que prueba que la teoría de la elección racional no es realista o adecuada.

Las bases de los principios del homoo economicus no pueden explicar convincentemente la emergencia del orden estable, porque cuando tiene preferencias estables no puede deliberar ni elaborar discurso. Aunque tengan información incompleta de las posibles opciones y de sus diferentes consecuencias, las opciones declaradas no son necesariamente estables. Los cambios en la conducta no se deben a cambios en las preferencias debido a la intensificación del discurso, sino a una información más completa. El principio de la estabilidad de las preferencias no origina la posibilidad que después del discurso, la gente prefiera opciones diferentes de aquellas que ha declarado.

\section{b) Enfoque de racionalidad social}

La economía política de la política social, es entendida como la intersección de los factores, económicos, políticos, sociales y culturales que afectan las elecciones de la política social. Las interpretaciones de las condiciones económicas de los actores son moderadas por una lógica institucional del más amplio medio ambiente que define las normas, valores y creencias que estructuran la cognición de los actores organizacionales y proveen el entendimiento colectivo para formular las decisiones de acuerdo a sus intereses. 
La racionalización es un proceso que involucra la emancipación de la tradición y que conduce a la diferenciación de la sociedad en distintas actividades y esferas de valor autónomas y con sus propias normas y obligaciones. Los diferentes estratos sociales tienen procesos de racionalización específicos y diferentes grupos sociales pueden responder en formas diversas a los tipos de racionalidad inherentes a los mitos racionalizados. Cada esfera de valor tiene patrones de acción y formas de vida que son definidas como racionales de aquellas otras esferas de vida que se consideran irracionales, lo que determina el concepto de lógica institucional. Los mitos culturales como un producto de la irracionalidad de las masas son el aglutinante necesario para la cohesión social y la unidad nacional. Sin embargo, hay un lado oscuro en el que la irracionalidad social se convierte en algo más que una profunda negación al servicio de la maldad.

El racionalismo constructivista ilustrado consideraba que la sociedad puede ser objeto de pleno conocimiento y de gobierno perfecto desde la ciencia. Hume (¿fecha?) propone que se da valor a la creencia que surge de una reflexión de nuestras percepciones imperfectas de la realidad y a una imaginación socavada por la razón.

Los valores sociales limitan la elección racional individual pero proporcionan nuevas posibilidades. Los valores sociales compartidos favorecen el sentido de pertenencia, fortalecen la identidad comunitaria y sustentan el mercado y el estado como mecanismos de integración y ordenamiento social.

La concepción de la racionalidad pública es consecutiva. La teoría de la utilidad esperada en el que a cada resultado se le asigna una utilidad y para cada opción en una situación de elección existe una probabilidad determinada que se convierta en un producto dado, por lo que a cada opción puede asignarse una utilidad esperada, es por lo tanto, una variante del enfoque consecutivo de la racionalidad, aunque no es la única posibilidad.

Así por ejemplo, la falta de incentivos adecuados para la participación ciudadana, por lo tanto, requiere del fortalecimiento del marco institucional. Los ciudadanos convertidos en meros "consumidores" adquieren la capacidad de ejercitar la elección racional por obra del libre mercado. Una vez tomadas las decisiones constitucionales, los costos externos potenciales de los individuos son pequeños, de tal forma que la participación es racional para los grupos de interés organizados.

En un modelo de economía política es necesario identificar la incidencia distributiva de las propuestas en consideración pero no en el ámbito de antecedentes de los bienes públicos. No es posible el análisis sin especificar cómo el bien público debe ser financiado. Una base 
conveniente implica un ajuste de beneficio que absorba impuestos como una distribución financiera neutral. Cuando los bienes públicos son un substituto perfecto para el consumo privado, la provisión mayor de un bien público financiado en una forma de distribución neutral no tiene efectos en la optimización de la distribución.

La incidencia distributiva de preexistentes bienes públicos es un principio relevante de lo cuánto la redistribución a través del esquema de la trasferencia de impuestos es óptima. Los bienes públicos afectan los niveles de utilidad de servicios de los individuos y las utilidades de los servicios marginales de consumo. Sin embargo, los datos relevantes relacionados con los niveles de utilidad de los servicios y las utilidades de los servicios marginales sin que se identifiquen como difieren en el nivel prevaleciente de bienes públicos y servicios.

\section{c) Teoría de la acción colectiva}

Los problemas de la acción colectiva se identifican como dilemas sociales entre la racionalidad individual o colectiva en situaciones donde la racionalidad individual de los actores queda atrapada para producir resultados no óptimos en términos de bienestar agregado. Existe un problema de acción colectiva cuando la acción individual racional se relaciona con resultados de bienestar inferiores al óptimo de Pareto el cual es el menos preferido por cada individuo. Los problemas de distribución que implican resultados eficientes y estables resultan en desigualdad en el óptimo de Pareto, lo que conduce a conflictos manifiestos. El óptimo y sub-óptimo de Pareto determina si el resultado de un juego implica conflicto entre la racionalidad colectiva e individual.

El nuevo papel del mercado aglutinado en los crecientes procesos de globalización y de tecnología es sustituir a los ciudadanos por simples consumidores siempre en función de su capacidad adquisitiva, desarticula la acción colectiva y diluye la solidaridad social. En la repetición infinita del "dilema del prisionero", los jugadores no tienen certeza acerca de las preferencias de los otros jugadores, la cooperación es la estrategia racional. La acción colectiva puede eliminar las restricciones y deficiencias del "dilema del prisionero" si se acuerdan metas en conjunto por todos los miembros de una comunidad. Las soluciones a la teoría de juegos incluyen estrategias mixtas, correlacionadas, secuenciales, interacción repetida, comunicación coordinativa y soluciones de punto focal.

Los diferentes tipos de problemas de acción colectiva desde la perspectiva de los mecanismos de solución pueden caer en las categorías de problemas de coordinación y problemas que implican conflictos. Los problemas de coordinación se resuelven mediante una variedad de mecanismos no cooperativos que trabajan en el ámbito individual y se 
basan en las expectativas racionales. Las expectativas racionales y monetaristas son una versión de la economía neoclásica la cual pone en conflicto a las políticas sociales con las políticas económicas. Gilbert y Michie (1997) concluyen al respecto que los supuestos de clarificación del mercado y de las hipótesis de las expectativas racionales de una economía no pueden desviarse sistemáticamente de su centro de gravedad o el correspondiente nivel de tasa natural de desempleo de los monetaristas. Es decir, sólo existen un único conjunto equilibrado de precios y por lo tanto de un nivel correspondiente de empleo y producto.

En lo que respecta al uso de las hipótesis de las expectativas racionales, estas se consideran como un modelo que todos los agentes representativos tienen en sus mentes, en donde no existen posibilidades de error sistemáticos, a menos que el modelo no sea verdadero cuya existencia implica una distribución objetiva de eventos futuros. Si la estructura del modelo no es independiente de las expectativas, entonces el modelo verdadero no existe y por lo mismo, si las expectativas son auto cumplen, entonces no existe una distribución objetiva que pueda ser explotada por agentes racionales. En la modelación económica por ejemplo, la cultura no es relevante porque no es tan obviamente racional. Por lo mismo, no encaja muy bien en la metodología del agente racional de la economía neoclásica (Hermalin, 1999).

Los juegos de coordinación implican el problema que los actores no sean capaces de coordinar sus estrategias en un equilibrio deseable. La mayor parte de las estrategias individuales basadas en las expectativas racionales trabajan con problemas de coordinación, los cuales también se pueden solucionar mediante mecanismos políticos.

Los problemas que involucran conflicto incluyen el desacuerdo, la distribución, la defección y la inestabilidad que se solucionan mediante mecanismos colectivos y coercitivos. Esos mecanismos para solucionar problemas de coordinación implican la muerte propia $\mathrm{y}$, aunque no son herramientas necesarias, pueden resolver todos los problemas. Cuando hay muchos jugadores, la regulación jerárquica de la coordinación puede ser eficiente, como en el caso de las reglas de tráfico. En los problemas de desacuerdo puede que la comunidad tenga de encontrar acuerdos autoimpuestos, sin embargo en los otros tres tipos de problemas de acción colectiva, se necesita la coerción. A pesar de que no siempre es efectivo, complementa los mecanismos políticos, aunque a veces puede reemplazarlos.

Los costos de la acción colectiva de quienes resisten el cambio institucional, como en el caso de los dictadores, no les resulta racional emprenderlo. Las soluciones políticas para los problemas de acción colectiva son procedimentales o institucionales basados en toma de decisiones y coerción colectiva. La propuesta de la teoría política clásica 
que no es del todo política es la solución Hobbesiana que delega todos los poderes a un soberano, quien procura a través de la coerción encausar todas las conductas de los actores en la cooperación, es decir, en la necesidad de tener un poder externo que imponga reglas y exija el cumplimiento de los contratos que solucionen de forma cooperativa los dilemas colectivos.

\section{d) La racionalidad económica de las decisiones}

Las investigaciones interdisciplinarias de las ciencias conductuales presentan evidencias sustanciales de que los individuos toman decisiones que se desvían del modelo teórico de la elección racional y de versiones limitadas de la racionalidad como un enfoque que se aproxima a la realidad, como consecuencia de las limitaciones cognitivas para procesar información, determinar los costos de información con relación a los costos de transacción y de las restricciones ambientales como las legales, y de los costos de información.

Coase (1937) introdujo y definió el término costos de transacción como los costos de usar el mercado y que da una racionalidad económica a la existencia de las firmas. De la racionalidad económica se deriva la racionalidad administrativa que busca la optimización, eficiencia y eficacia de la provisión de bienes públicos en las organizaciones del sector público mediante el empleo de técnicas, métodos e instrumentos gerenciales que se aplican en las organizaciones privadas con fines de lucro.

El concepto de racionalidad es más amplio que el dominio de la racionalidad formal, instrumental, con un propósito, o medio-fin. La racionalidad limitada y los costos de transacción positivos están relacionados. En condiciones de incertidumbre, las probabilidades no se atan a un número finito de eventos como en el caso de situaciones de riesgo donde es posible calcular los valores esperados bajo el marco de referencia de la teoría de las decisiones. En condiciones de incertidumbre, la racionalidad perfecta tiene poco sentido, por lo que Simon (1955) denominó como racionalidad limitada.

El concepto de racionalidad perfecta o completa es incompatible con el discurso debido a las limitaciones de su capacidad para predecir los sucesos y para evaluar los resultados de las diferentes alternativas para decidir óptimamente en un instante y con los menores costos. Información incompleta y disparidad y división del conocimiento disponible requieren de la comunicación para la generación de nuevas ideas Los actores tienen información incompleta acerca de las diferentes consecuencias de las normas alternativas. La denominada ignorancia racional en economía hace alusión a la participación de los individuos en un discurso en donde todos los miembros de la sociedad son afectados pero en el cual su impacto en los resultados de las diferentes alternativas es marginal. 
Para Habermas (1992), los modos del discurso son pragmáticos, éticos, políticos y morales, totalmente diferentes a las negociaciones, en donde las representaciones estratégicas de las preferencias son importantes y los rasgos de los participantes son importantes. La racionalidad de las reglas en condiciones de incertidumbre justifica el uso de guías de acción y reglas para determinar la conducta bajos ciertas situaciones.

La teoría económica de la forma de contratos asume un tipo de conducta racional de parte de compradores denominada como la teoría de la utilidad esperada de acuerdo a la cual se espera que los compradores usen el mercado para maximizar su utilidad esperada, supuesto conductual que no parece objetable si se considera que los individuos tienen diferentes metas, pero que todos intentan satisfacer sus metas de forma tan económica como sea posible, lo que nos lleva a hipótesis acerca de los supuestos de tomas de decisiones.

La teoría económica predice formas contractuales que contienen términos eficientes implícitamente, que se fundamentan en supuestos de que los compradores emplean comparaciones de costo-beneficio de forma compensatoria y no selectiva entre todas las posibles alternativas de productos que consideran, aunque con limitaciones cognitivas y restricciones externas en tiempo y esfuerzos, todas las posibles decisiones son elaboradas en un marco de racionalidad A pesar de que el mercado espera proveer términos contractuales eficientes que den ventajas tanto a los compradores como a los vendedores, tales términos no siempre son del todo defendibles.

Las formas de los contractos contienen términos ineficientes porque la conducta racional de toma de decisiones de los compradores previene al mercado de asegurar que los vendedores ofrezcan solamente términos eficientes. No resulta tan obvio que proveen el peor resultado posible en bienestar social y en bienestar del comprador con respecto a las alternativas disponibles.

Las evidencias de que la toma de decisiones en función de elección racional se desvía sistemáticamente de los supuestos de la maximización de la utilidad, el interés propio y la maximización de la riqueza requiere que los consecuencialistas reemplacen sus preferencias por mercados no regulados con mayor agnosticismo inicial concerniente a la competencia institucional relativa a los mercados y la intervención del gobierno.

El modelo clásico racional de toma de decisiones que marca etapas sucesivas claramente distinguibles es diferente del modelo de interacción estratégica. La teoría de la elección racional, de acuerdo a Coleman, es aquella en la cual cada actor tiene control sobre ciertos recursos y beneficios en ciertos intereses y eventos. La existencia de al menos dos actores y el control de recursos es la base del sistema social. En la teoría de las decisiones colectivas de Coleman (1988) se integra lo micro y lo 
macro social sobre la base de la teoría de la elección racional considerando al capital social como recurso de los actores en forma de obligaciones y expectativas, capacidad de fluencia de información de la estructura social y las sanciones de las normas.

Los microsucesos son la forma de acción e interacción subjetiva en la que tanto por rutina y presencia sistémica toma forma la estructura social que institucionalizan los sujetos en la interacción, (Giddens 1984:170-173). La formulación de políticas económicas se fundamenta en el equilibrio de la interacción racional de los agentes económicos.

La conducta de toma de decisiones es altamente contingente del contexto que hace posible identificar la estrategia específica que el comprador usa al hacer decisiones de compra en el mercado, o una lista precisa de los atributos sobresalientes y no sobresalientes. Si la cantidad de información relevante se incrementa, las decisiones incrementan en complejidad, lo que demanda grandes esfuerzos cognitivos.

\section{ENFOQUES DE LA ECONOMÍA POLÍTICA}

\section{a) Economía normativa}

La economía normativa inicia con el precepto de que el bienestar social es determinado por el bienestar individual de los miembros de la sociedad. Los economistas usan el modelo estándar de racionalidad para predecir la conducta bajo un nuevo régimen de políticas para evaluar las políticas de acuerdo a su impacto en el bienestar de las personas afectadas. Para los economistas constitucionales normativos los acuerdos legitiman las reglas que requieren de explicación de la voluntad de los actores para invertir en información relacionada con las propiedades de las reglas constitucionales.

Para quienes sostienen la perspectiva de la ética discursiva, están interesados en la verdad de los juicios desde un enfoque de información incompleta y racionalidad limitada, mientras que desde la economía del bienestar hace énfasis en los resultados concretos. Para evaluar una institución económica se debe tener un modelo de profecías que puede servir como la base para los juicios significativos de bienestar.

\section{b) Economía política comparativa}

La economía política comparativa ofrece diferentes análisis de desarrollos en la economía política global. Los problemas del desarrollo son multifacéticos y complejos. Algunos de los desacuerdos sobre el desarrollo en el presente estado de globalización, son el diagnóstico sobre el desarrollo desigual, sobre evaluación de los méritos y deméritos de los caminos del desarrollo en las últimas décadas, y sobre las direcciones prescriptivas de las decisiones de políticas. 


\section{c) Economía política positiva}

De acuerdo a Shepsle and Weingast (1994) la economía política positiva es el estudio de las decisiones racionales en un contexto de instituciones políticas y económicas. La economía política hace énfasis en la conducta política en los procesos económicos y la conducta económica en los procesos políticos. Por lo tanto, en una sociedad con mayor énfasis en los procesos políticos que los económicos, el Estado asignará los recursos en función de objetivos sociales y políticos y en una sociedad donde el mercado tiene una función prioritaria sobre los procesos políticos, el Estado tendrá poca intervención en la asignación de los recursos que se hará mediante mecanismos de precios. Ello, a pesar que contradice el principio que sostiene que las intervenciones del Estado para eliminar los riesgos de las inversiones alientan la ineficiencia del mercado.

En realidad, ninguna disciplina científica por sí sola puede ofrecer soluciones al desarrollo y abarcar todo el campo de estudio. Los economistas políticos consideran que los economistas no separan las teorías y las técnicas usadas en el medio ambiente político en el que opera la economía. No existe posibilidad de un tipo de distinción positivo/ normativo en el cual toda la teoría y las prescripciones de las políticas deben tener lugar en un marco de referencia institucional.

\section{d) Economía política del mercado}

La dinámica de la economía política del mercado subordina a su propia lógica a la sociedad y a la política. Los efectos societales que tiene la economía de mercado hacen que se convierta en economía política de mercado. La economía de mercado determina la cultura de la sociedad bajo el móvil de la ganancia. La economía de mercado es un sistema político-económico que constituye la antítesis de una sociedad en donde se dé prioridad a lo social y a lo político por sobre lo económico, porque organiza la producción, distribución y consumo de bienes y servicios que requiere una sociedad. La economía de mercado sólo funciona en una sociedad de mercado que organiza la producción y distribución de los medios materiales para su subsistencia y que, por lo tanto, la actividad económica provee los bienes materiales que sirven de sustento para la reproducción de la sociedad. La economía de mercado requiere de instituciones que facilitan los intercambios.

El desarrollo de Inglaterra se sustentó en las tesis de la economía política clásica elaborada por los ingleses Adam Smith, Thomas R. Malthus, David Ricardo y el francés Jean Baptiste Say, basada en el ahorro, en el trabajo y en el libre comercio. Pero la aplicación de estas tesis son contradictorias e incompatibles con "el empleo sistemático del poder político, militar y económico del país en una praxis de colonialismo, proteccionismo y explotación de los pueblos bárbaros" (Dietererich, 2002). 
Friedrich List, formador del capitalismo del Estado Alemán a finales del siglo XVIII y principios del XIX, critica esta doble moral inglesa, la cual se sintetiza en el análisis de Dietererich (2002) porque desde "la constitución del moderno estado inglés en la dictadura desarrollista de Oliver Cromwell tal como se había manifestado en el Acta de Navegación (1651) y el monopolio de la East India Company hasta los días del encantador Tony Blair, la única política real de crecimiento económico ha sido el capitalismo proteccionista de Estado". La noción de crecimiento económico queda limitada a una medición cuantitativa del producto interno bruto per cápita y a la determinación de un promedio real de consumo.

\section{e) Economía institucional}

La economía institucional estudia la economía de los costos de transacción, la economía de los derechos de propiedad, la teoría del principal agente, los enfoques de economía constitucional y elección pública.

El enfoque de la economía institucional sobre el desarrollo se hace desde dos perspectivas teóricas, la teoría de la información imperfecta y el análisis comparativo de los procesos de desarrollo, las cuales fundamentan los arreglos institucionales. El estudio de la racionalidad facilita el análisis de la estabilidad de los arreglos organizacionales, su inercia, cambio y conflicto. El impacto de los cambios de la racionalidad en las identidades individual y organizacional es una importante dimensión de la teoría institucional (Townley, 2002). Según Parsons (1960) el nivel técnico de las organizaciones se convierte en el racional que busca una eficiente producción. Así, las estructuras y formas organizacionales son irracionales o no racionales en su carácter.

Las fuerzas institucionales y racionales son fuentes alternativas de estructuras y conductas no necesariamente en conflicto, sin embargo se reconoce que los procesos institucionales sobrepasan a los racionales mediante el establecimiento de reglas de racionalidad. Las reglas institucionales inventan la racionalidad. El énfasis original de Weber es en analizar el cambio institucional, analizando las dimensiones de la racionalidad, lo que requiere un cambio de énfasis de la acción racional a las formas de racionalidad.

Los regímenes políticos son arreglos institucionales que facilitan las diferentes interrelaciones entre los actores. Al respecto, North (1991) argumenta que "La teoría macroeconómica nunca resolverá los problemas que confronta a menos que se reconozca que las decisiones adoptadas en el proceso político afectan críticamente el funcionamiento de la economía. Esto sólo puede hacerse mediante una modelización del proceso económico-político que incorpore las instituciones específicas afectadas y la consiguiente estructura del intercambio político y económico". 


\section{f) Instituciones}

Las instituciones regulan el comportamiento social y su ambiente económico, por lo que el cambio de este entorno requiere también de cambios institucionales. La economía política de los cambios institucionales intenta identificar los intereses e incentivos de los actores y agentes que pueden dar lugar a acciones colectivas oportunistas o coordinadas y las coaliciones.

Las instituciones y las normas constituyen la base del funcionamiento interrelacional que determina el grado de racionalidad instrumental entre los diferentes actores del Estado (gobiernos, burócratas, políticos, etc.) el mercado (propietarios privados) y la sociedad civil.

En la dimensión de racionalidad, las reglas institucionales inventan la racionalidad. En las instituciones externas, la ausencia de cumplimiento de las reglas se sanciona por los representantes del Estado y en las instituciones internas la falta de cumplimiento se sanciona por los miembros de la sociedad con variaciones que dependen del tiempo y el lugar. Los actores pueden elegir entre las leyes de las instituciones externas y las tradiciones de las instituciones internas. Las instituciones internas tienen influencia recíproca con las instituciones externas de la sociedad. La evidencia sobre la relativa importancia de las instituciones internas incluso si las instituciones alternas relativas están disponibles, parece apoyar la hipótesis de que las instituciones internas son más estables que las instituciones externas. Cuando las instituciones externas no funcionan, los agentes económicos realizan esfuerzos para compensar las inadecuaciones legales.

La razón práctica (phronesis), como una virtud aristotélica, contrasta con la lógica del instrumentalismo, así como la acción racional contrasta con la acción práctica, como un argumento constructivista social que toma en cuenta la situación y el contexto que guían la acción y proveen el marco de referencia para la acción razonable. La racionalidad normativa muestra un movimiento de la organización a la institución, que legitiman las elecciones organizacionales en referencia a la misión y valores de la organización que sostiene la integridad organizacional. En la teoría institucional, la relación entre racionalidad y conducta institucional es ambigua.

\section{g) Institucionalismo}

El institucionalismo de la primera mitad del siglo XIX tenía una orientación descriptiva y usaba el razonamiento inductivo.

La sociología política y el institucionalismo de la ciencia política fundamentaron conceptualmente la noción del buen gobierno empujando la instauración de procesos de gobernabilidad democrática y el análisis de los procesos de informalización de la política. El buen gobierno, 
esencia de la gobernabilidad democrática, se centra en los procesos de formulación y ejecución de políticas públicas creadoras y reguladoras de instituciones y mecanismos que permitan a los actores colectivos, acordar, negociar y asumir funciones de vigilancia de la esfera pública.

Los instrumentos del institucionalismo se aplican a la ciencia política en el análisis de los procesos de disolución como una inevitable acción de diferenciación social latinoamericana. La sociología política describe la complejidad y la fragilidad de la inserción de la sociedad civil en la esfera pública y endereza las críticas hacia el modelo de desarrollo neoliberal impuesto por el estado.

\section{ECONOMÍA POLÍTICA INSTITUCIONAL}

La economía política institucional proporciona las bases para la lógica de la gobernabilidad al considerar las consecuencias de las formas institucionales alternativas en la conducta de los individuos y en los resultados de las decisiones colectivas, los mecanismos que posibilitan a las instituciones constreñir los comportamientos y la lógica de los procesos a través de los cuales cambian las instituciones (Weimer, 1995, 2). En la racionalidad "adaptativa", determinadas conductas son recompensadas y otras son castigadas, es decir la conducta está sujeta a restricciones no son aceptadas y cuyas predicciones son difíciles de determinar bajo los modelos del homo economicus. La eficiencia adaptativa aparenta tener más importancia que la eficiencia de asignación en los resultados del desarrollo.

Las formas de gobernanza públicas o privadas no ofrecen los elementos para la fijación de estándares. Los diferentes tipos de estándares requieren diferentes formas de gobernanza, ya sea las organizaciones formales públicas y privadas y la descentralización más identificada con el mercado. Sin embargo, el análisis institucional comparado facilita la elección de mecanismos de gobernanza.

\section{INSTRUMENTACIÓN CONTEMPORÁNEA DE LOS MODELOS DE ECONOMÍA POLÍTICA}

La teoría de la modernización sostiene que el desarrollo social y político de los pueblos ocurre en el cambio de racionalidad de una sociedad basada en los afectos a una sociedad basada en los logros individuales. Esta teoría identificó etapas evolutivas de desarrollo de los pueblos.

Los siguientes 25 años al término de la Segunda Guerra Mundial fue una época de crecimiento sostenido (1945-1970) que dio lugar a dos décadas de resultados económicos, políticos y sociales dentro de una economía política cambiante. No menos importante entre estos 
resultados y predicciones fue la expectativa que los factores demográficos responderían a la modernización y que en articular, las tasas de fertilidad declinarían. Los resultados recientes han invalidado estas expectativas.

Las teorías de la modernización no predijeron bien otras consecuencias de estos procesos de difusión. La reacción a los errores predictivos al acercamiento de la modernización no surgió primero de la sociología Norteamericana sino de su contraparte Latinoamericana fuertemente influenciada por la economía política marxista. El marxismo es un acercamiento dialéctico al desarrollo de la humanidad y un enfoque desde el materialismo histórico para señalar la lucha de clases que evoluciona del desarrollo capitalista a una sociedad socialista integrada por un sistema de producción, distribución y consumo formado por individuos iguales en un Estado democrático.

Con estas raíces teóricas firmemente plantadas en la economía política marxista, los trabajos sobre la dependencia dejaron de lado todas las consideraciones de valores e ideas y culpó de la pobreza del Tercer Mundo a las corporaciones multinacionales y sus gobiernos protectores.

El Consenso de Washington articula un programa de economía política global y de reestructuración del sistema político basado en la gobernabilidad democrática, en torno al libre mercado como pensamiento único dominante. La estrategia del Consenso de Washington como el único modelo para el desarrollo bajo una economía de control nacional basado en imponer la democracia, el libre mercado y comercio en cada rincón del globo, aunada a la estrategia de guerra preventiva para la consolidación de supremacía militar, mantiene a Estados Unidos como la economía del imperio.

La aplicación de este evangelio enfatiza el carácter de un sistema intelectual cerrado que supone como la única libertad real a la libertad comercial. El carácter normativo y de racionalismo instrumental de las políticas económicas formuladas por el Consenso de Washington está orientado por procesos políticos de los participantes que tienen suficiente voluntad política para buscar la obtención de los mejores resultados de acuerdo a sus propios intereses estratégicos. Así, las diferencias de intereses de clase entre las naciones se obscurecen en categorías abstractas.

Así por ejemplo, el cambio institucional de los servicios públicos con una orientación hacia la acción social centrado en los valores de la cultura cívica y en los valores del capital social es muy complejo, debido a la racionalidad instrumental del enfoque de la eficiencia económica.

\section{a) Economía política internacional}

La geografía política y económica del espacio estatal está cediendo su lugar a la geografía política y económica en los ámbitos internacionales, regionales y mundiales. 
El análisis de la globalización desde la economía política internacional estudia su naturaleza capitalista en el contexto del sistema internacional en el cual los actores llevan a cabo sus operaciones, así como la transnacionalización de sus causas y efectos. El poder capitalista o hegemón cuenta con los recursos y el poder para imponer como una hegemonía transnacional las reglas del desarrollo del capitalismo global a través de estructuras supranacionales. Bajo este análisis, la estructura transnacional de actores financieros y económicos se sobrepone, cubre, suple, rodea, limita e intercepta al Estado-nación.

La globalización de los mercados es producto de los acuerdos comerciales entre los Estados y del crecimiento de las empresas transnacionales. Todos los acuerdos comerciales han sido promovidos y negociados por los Estados para abrir mercados nacionales a sus empresas transnacionales. Las contribuciones de la gobernabilidad en los acuerdos de cooperación internacional han crecido "pero sin progresos sustantivos en los soportes operacionales y con fuertes diferencias sobre los contenidos" (Saldomando, 2002). La relación de los mercados nacionales diferentes en un acuerdo comercial genera de otros acuerdos que implican reformas institucionales.

Por otro lado, la teorización holística de la economía política internacional es una forma contestataria de la creciente globalización neoliberal y a la correlativa representación democrática. La ideología neoliberal que fundamenta la economía capitalista impulsa los procesos de globalización. La globalización neoliberal es la hegemonía de la ideología del mercado representada por una "metáfora incontroversial por una sociedad en libertad para hacer con la propiedad lo que le plazca sin interferencia del Estado" (Birchfield, 1999). El modelo neoliberal de globalización sólo concibe la coordinación de mercados anónimos para la asignación global de los mercados.

De hecho, la globalización es vista aquí como un conjunto de estructuras y procesos económicos, sociales y políticos que derivan de un carácter cambiante de los bienes y activos que comprenden la base de la economía política internacional, y más particularmente la diferenciación estructural creciente de estos bienes y activos (Lawrence, 1996).

La globalización constituye una etapa superior del desarrollo mundial del capitalismo que surge a partir de cambios radicales y profundos en la economía política y la política económica fundamentadas en el neoliberalismo que pretende transnacionalizar su impacto. También puede entenderse los actuales procesos de globalización como resultado de una tendencia continuada por lo menos en los últimos cinco siglos, del desarrollo del capitalismo, hasta llegar a la fase actual denominada neocapitalismo o capitalismo tardío, mediante el análisis más detallado de sus rasgos característicos que muestran diferentes manifestaciones y formas de expresión. 
Las transformaciones económicas y políticas también implican transformaciones de los valores sociales, culturales y sobretodo de valores morales. Para la transformación de la sociedad es necesario disponer de instrumentos de diagnóstico y de análisis de los sistemas reales que determinen que es lo transformable.

La multidimensionalidad de la globalización está estrechamente vinculada con la idea de conectividad compleja como una condición del mundo moderno (Tomlinson, 1999). Por conectividad compleja, el autor entiende que la globalización se refiere a la red de interconexiones e interdependencias que rápida y densamente se desarrollan y que caracterizan la vida social moderna. El pensamiento social burgués separa los dominios económico y político de la vida social (Amín, 2001) mediante la adopción de diferentes principios específicos.

La ideología de la democracia del libre mercado constituye el cuerpo teórico y la práctica de la política de desarrollo internacional, pensada como problema de gobernabilidad para establecer las reglas de juego a los agentes económicos. Los agentes económicos realizan transacciones mediante el uso de contratos, normas y procedimientos estandarizados para obtener economías de escala, reducir costos de transacción y una mayor eficiencia en las operaciones internacionales. El imperio absoluto del mercado como la única forma de gobernabilidad congela el orden de cosas existente, descalifica y censura toda alternativa posible.

La teoría de la democracia interceptada con el enfoque de la economía política internacional comparativa para analizar el fenómeno de la globalización, tal como lo conceptúan las agencias internacionales, como el Banco Mundial, tiene muchas limitaciones. La principal es que ofrece un marco de referencia opuesto, de acuerdo al análisis de Birchfield, (1999) quien examina la globalización económica neoliberal desde la perspectiva de la teoría de la democracia y, además, critica la ideología del mercado para deslegitimar el pensamiento político como un punto de partida para la acción democrática. La teoría de transiciones encuentra barreras institucionales para consolidar la democracia que no se corresponde necesariamente con una política moderna, ni tampoco con una mejor distribución de la riqueza.

Los nuevos movimientos sociales contra la globalización neoliberal, a partir de Seattle, consolidan el agotamiento teórico y práctico del neoliberalismo y cuestionan tanto la efectividad de esas políticas como su pretensión de ser las únicas viables. El movimiento altermundista tiene sus antecedentes en los últimos 20 años en los países menos desarrollados aunque se manifiesta fuertemente desde Seattle, en 1999, en los países más desarrollados como un movimiento de democratización que se contrapone a la imposición de políticas neoliberales. 
Para el movimiento altermundista el modelo de desarrollo económico neoliberal es inviable porque ha agotado sus alcances, los procesos de globalización se encuentran en crisis de legitimidad y credibilidad porque se ha profundizado la depresión económica mundial y urge a cambiar el rumbo económico. Los altermundistas proponen una organización mundial de comercio equitativo que reemplace a la actual OMC que formule la política comercial mundial bajo las mismas reglas que siguen los países desarrollados para que las sigan los menos desarrollados sobre las premisas de respeto a los derechos humanos y al interés público de los pueblos que buscan el desarrollo sustentable.

\section{b) Nuevo institucionalismo}

El neoinstitucionalismo económico relaciona de forma inextricable la economía y la política y analiza las fallas de los mecanismos del Estado y sus ineficacias. El papel de los valores es central al viejo institucionalismo pero el neoinstitucionalismo se orienta más a los procesos cognitivos. El institucionalismo de la primera mitad del siglo XIX tenía una orientación descriptiva y usaba el razonamiento inductivo.

El neoinstitucionalismo que aglutina enfoques históricos, sociológicos y de la elección racional, surge a principios de la década pasada como un conjunto de reglas que determina los procesos de la reforma institucional a partir de los marcos de incentivos y restricciones impuestos a los comportamientos de los diferentes agentes y actores económicos, sociales y políticos para la formulación e implantación de políticas públicas y que tienen un impacto en los resultados medidos en términos de crecimiento y desarrollo.

El nuevo institucionalismo se cimienta en un individualismo metodológico que se fundamenta en el principio de que todos los resultados de las acciones humanas se explican por la acción individual cuyas interacciones en las estructuras legitiman las instituciones. Este individualismo metodológico tiende a incentivar a los individuos en función de sus acciones.

El neoinstitucionalismo se fundamenta más en el razonamiento deductivo y se expresa en dos grandes enfoques: en la elección de las estructuras de governance de los actores privados en un determinado medio ambiente que se convierte en el objeto de análisis económico y en el cambio institucional en función de los efectos que los diferentes medios ambientes institucionales tienen en el desempeño económico y en el desarrollo de las instituciones con el apoyo de modelos mentales compartidos e ideologías.

El surgimiento espontáneo de las instituciones en las sociedades se explica por los modelos mentales compartidos e ideologías que determinan las percepciones de los actores en situaciones de interacción 
en las cuales la cultura y creencias conductuales tienen un papel relevante. Las estructuras de governance se convierten en híbridas en un continuo que va de la empresa en un extremo al mercado en el otro. La creación de medios ambientes empresariales data de poco más de un siglo. Sin embargo, las formas de governance privadas globales van más allá de la simple coordinación de mercados anónimos.

La globalización no es un proceso unilineal que transforma las estructuras de governance de producción, distribución y consumo del nivel de las economías nacionales en una economía global, sino que también en forma paralela que desarrollan estructuras de governance privadas globales tales como la formación de sistemas de redes globales de valor agregado y casi jerarquías para integrar a los emplazamientos locales en los procesos de producción, distribución y consumo de los mercados mundiales.

Entre el enfoque neoinstitucionalista y el de regulación democrática emerge el concepto de gobernabilidad como una relación existente entre los procesos de libre mercado y los procesos de la democracia. El mercado libre se soporta sobre una estructura institucional y jurídica, es decir, sobre un orden público económico concebido como el "conjunto de medidas adoptadas por los poderes públicos con el objeto de organizar las relaciones económicas y cuya función es la dirección y protección de la economía" (Streeter Prieto, 1985).

El neoinstitucionalismo pretende ordenar la esfera pública bajo un esquema de instituciones orientadas más al ordenamiento privado que aniquila toda pretensión de igualdad económica, social y política, a partir del supuesto de que ya han sido obtenidas por el régimen democrático. Norberto Bobbio sostiene que "con una redundancia se puede definir el gobierno de la democracia como el gobierno del poder público en público", añadiendo que "el régimen democrático ha sido definido como el gobierno directo del pueblo o controlado por el pueblo", por lo que resulta válido formular la pregunta acerca de "¿cómo podría ser controlado si estuviese escondido?" El poder del gobierno no puede ser arbitrario sino que tiene que ser limitado.

De acuerdo con Prats (2002), "El mensaje del neoinstitucionalismo económico es una buena nueva para la democracia liberal: en las condiciones actuales las instituciones necesarias para definir y garantizar los derechos individuales requeridos para el mayor y mejor desarrollo económico no sólo son compatibles sino que son las mismas necesarias para disponer de una democracia duradera" (Olson, 1993; citado por Prats, 2002). Los componentes del concepto de la democracia liberal son el control del Estado y de sus decisiones y asignaciones se fundamentan en las autoridades electas, un poder ejecutivo limitado por otras instituciones estatales autónomas, el respeto y reconocimiento 
de derechos a las minorías culturales, étnicas y religiosas, multiplicidad de canales de comunicación, expresión y representación de los intereses partidistas y de grupos, etc.

Para Olson (1993, citado por Prats, 2002), el razonamiento es sencillo: dada una asignación eficiente de los derechos de propiedad (que no consolide sino que impida capturas de renta en el proceso político-económico), las personas y las organizaciones para ser económicamente eficientes necesitan un gobierno seguro que respete los derechos individuales y que genere un entorno de respeto a la propiedad ganada y de cumplimiento de los contratos a través en última instancia de una justicia imparcial.

El neoinstitucionalismo estudia los rasgos de las estructuras institucionales económicas que posibilitan el desarrollo de los pueblos. El neoinstitucionalismo enfatiza las instituciones que definen el comportamiento de los actores frente a su medio social. El neoinstitucionalismo económico analiza las fallas de los mecanismos del Estado y sus ineficacias. La economía neoinstitucional demuestra las deficiencias e incapacidades del Estado como mecanismo de gobernabilidad y coordinación que garanticen los acuerdos y compromisos sobre la propiedad.

El nuevo institucionalismo atiende a los campos organizacionales como unidades de análisis. Los procesos institucionales pueden dar cierta estabilidad a los campos organizacionales, aunque estos siempre están evolucionando y no son estáticos, resolviendo mediante consenso negociado socialmente las diferencias de interpretación.

Es cuestionable en la teoría económica neoinstitucional el hecho de que las instituciones disfuncionales que no alcanzan los niveles óptimos, permanezcan durante mucho tiempo y prolonguen el subdesarrollo, debido a causas fundamentalmente de mecanismos de autorefuerzo en procesos de dependencia. De acuerdo a la teoría neoinstitucional de la economía, el subdesarrollo es resultado de las fallas del Estado para proveer las estructuras de governance necesarias para garantizar las instituciones que apuntalan el desarrollo de los pueblos. El neoinstitucionalismo recomienda un Estado fuerte pero limitado en sus funciones. El contenido del Estado es sólo garantizar al mercado la posibilidad de ejercer su función sin obstaculizar su trabajo y protegerlo de injerencias ajenas (Estefanía, 2002).

De acuerdo a Burgos Silva (2002), el análisis económico neoinstitucionalista define la institucionalidad jurídica y el desarrollo económico, cuestiona el derecho como instrumento del desarrollo económico y reconoce a las instituciones informales y promueve mecanismos institucionales considerados como óptimos. La teoría neoinstitucionalista argumenta que la importancia de los marcos de 
referencia normativos y las reglas de comportamiento para guiar, constreñir, y crear poder en las organizaciones las que se consideran consisten de estructuras y actividades cognitivas, normativas y regulativas que dan significado al comportamiento social.

Una crítica al neoinstitucionalismo es que diseña arreglos institucionales con criterios óptimos de implantación en los países más desarrollados, los cuales son seriamente cuestionados por el path dependence para ser adaptados en los países menos desarrollados.

\section{NUEVA ECONOMÍA}

El mayor cambio en la tecnología de la información es desmembrar el desempeño de la propiedad de los activos. El período comprendido entre 1860 y 1900 es con frecuencia denominada como La Segunda Revolución Industrial debido al gran número de tecnologías inventadas durante ese tiempo. Posteriormente hubo un lapso de tiempo de varias décadas antes que las nuevas tecnologías se difundieran ampliamente hasta llegar a la Nueva Economía caracterizada por un crecimiento rápido en productividad. Seguido a la Revolución de la Tecnología de la Información se genera relativamente una difusión rápida y una transición.

Las nuevas tecnologías de la información y de la comunicación instrumentalizan la comunicación política y transforman la práctica económica. Los procesos de desarrollo tecnológico se relacionan con los procesos socioculturales organizados en estructuras sociales y políticas cada vez más complejas, reguladas y especializadas, con una mayor concentración del poder económico y político que excluyen importantes estratos sociales. Mientras que los países menos desarrollados tienen que comprar la tecnología, producen abundante mano de obra en condiciones laborales inadmisibles que añaden valor a los productos diseñados y distribuidos en los países más ricos.

La interacción de la revolución de la tecnología de la información y la comunicación, la crisis del Estado benefactor y del capitalismo y el surgimiento de los nuevos movimientos sociales han provocado la formación de una nueva estructura social hegemónica que Castells (¿fecha?) denomina la "sociedad-red", la nueva economía basada en lo informacional/global y una nueva cultura con fundamento en la virtualidad real. La creación virtual del capital en el mundo digital desaparece la noción del tiempo como factor para la acumulación.

La información como la materia prima fundamental en la Nueva economía es abundante en los países desarrollados que transforman, distribuyen y consumen, costosa en la generación del conocimiento pero con costo marginal cercano a cero cuando se vuelve accesible para incrementar las unidades producidas gracias a la revolución de las 
tecnologías de la información y las comunicaciones. La perspectiva sociopolítica demuestra los nexos del conocimiento y la sociedad existentes en el financiamiento, producción, uso y distribución de la ciencia con su contexto económico social. El conocimiento como materia prima tiene un efecto multiplicador en la competitividad como resultado de la organización del trabajo en red y se genera la economía informacional centrada en el conocimiento como una nueva forma de producción que atraviesa todos los sectores económicos.

Las deficiencias institucionales de los mercados financieros bloquearon el desarrollo en algunos países. Los signos de agotamiento del neoliberalismo se presentaron a partir de las crisis financieras regionales iniciadas con la mexicana en 1994 y con el caos provocado por la dinámica de la nueva economía, que pretendió ser la locomotora de la economía global, entró en crisis en el 2001. El reconocimiento de que los resultados del modelo de globalización implementado hasta ahora, orientado por las grandes corporaciones a través de sus burocracias, con sus inevitables crisis económicas y financieras, no han sido los esperados, cuestiona su legitimidad.

La denominada Nueva Economía como estrategia de desarrollo ha fracasado en sus expectativas fundamentalmente a que los criterios de rentabilidad son los mismos que la economía tradicional basada en el capitalismo industrial avanzado que genera la plusvalía en beneficio del capital y en detrimento de la suma del trabajo y la información, pero en donde además, la información tiende a sustituir al capital que en sí mismo es información y por lo tanto también tiende a sustituir al trabajo. Así, la teoría de la plusvalía como base de la acumulación del capital, generada por la fuerza de trabajo deja de tener actualidad.

Las nuevas tecnologías deben administrarse de tal forma que beneficien a los pobres. Aumentar la velocidad y reducir costos de las comunicaciones y el conocimiento tienen un papel importante que jugar para permitirles a los excluidos y pobres tener acceso a los beneficios de la globalización. La relación sujeto-objeto cosifica lo que se estudia y los sujetos del conocimiento son afectados por las transformaciones en los estudios sociales. La acción internacional es esencial para asegurar a los países y comunidades pobres para que tengan acceso a la "nueva economía" y que se reformen algunas de las reglas existentes que previenen la transferencia de tecnología a los pobres.

\section{NUEVA MACROECONOMÍA CLÁSICA}

La Nueva Macroeconomía Clásica que tiene como premisas fundamentales los mercados libres y la optimización de los agentes que actúan de acuerdo con la hipótesis de las expectativas racionales, 
enfatizando la naturaleza racional de las expectativas y el problema de la inconsistencia del tiempo en la implementación de políticas, describe un sistema económico estable.

Al final de los ochentas, el fin del bloque soviético dio el empuje final hacia la consolidación de la teoría neoclásica como la dominante, como el único acercamiento mayor al desarrollo nacional, con las estrategias de crecimiento más centradas en el Estado, tales como las de los estados comunistas, ahora desacreditados, el camino estaba libre para la expansión global del capitalismo y con ello la hegemonía de la escuela teórica más orientada al mercado. La referencia espacial del desarrollo se ha movido del nivel nacional con el debilitamiento del Estado nación al nivel supranacional y local con el fortalecimiento de los bloques regionales de integración y con la descentralización de funciones en los gobiernos locales.

La Nueva Macroeconomía clásica clama por reglas para controlar las políticas emanadas de la intervención del Estado en gran escala, contribuyendo a la efectividad de las políticas y a limitar la extensión de la interferencia gubernamental en la economía, rechazando por lo tanto todo tipo de intervencionismo del Estado en las actividades económicas.

Un curso más apropiado de acción es examinar que factores se pierden del análisis neoclásico de los determinantes del desarrollo de tal forma que los resultados pueden predecirse en forma más segura. Si bien este sistema económico se conforma de agentes racionales que tienen o actúan como si tuvieran, un entendimiento claro de la economía, pero no hay una mención explícita a los factores institucionales que tengan la implicación de que estos están cambiando.

Los economistas deben tener conocimiento de ello cuando desarrollan sus teorías, aunque la Nueva Macroeconomía Clásica ignora los factores institucionales y encuentra apoyo en la teoría de la elección pública (Gilbert and Michie, 1997). La teoría de la elección pública explica el comportamiento económico y político en función de la búsqueda de maximización de los beneficios de los individuos que realizan diferentes interacciones en un contexto institucional el cual logra determinado equilibrio entre los principales agentes económicos y actores que realizan estrategias de negociación, competencia, formación de alianzas y coaliciones, etc. Esta concepción de la elección pública he derivado en el fundamentalismo del mercado que considera que todo tipo de las interacciones humanas son reducibles a simples transacciones de mercado.

Las elecciones privadas de los consumidores pueden ser más modeladas y manipuladas, no son autónomas e independientes y son totalmente diferentes a las elecciones cívicas que hacen los ciudadanos. A pesar de estas consideraciones, la "lógica de las ganancias privadas" se ha impuesto sobre la "lógica de los bienes públicos" en donde entran los 
mecanismos de competencia a generar y proveer los bienes públicos como bienes privados, derivando en situaciones similares a las mostradas en el Dilema del Prisionero, como la peor solución. A tal grado, que la teoría de la elección pública considera que el supuesto de la maximización de la utilidad racional debe de extenderse a todas las instituciones incluyendo el mismo gobierno, ya que está compuesto de individuos que también observan conductas e búsqueda de la maximización de los beneficios..

Sin embargo, se invalida el soporte que la teoría de elección pública hace para la Nueva Macroeconomía Clásica la cual tiene un fuerte componente basado en el supuesto de las expectativas racionales, supuesto que ha universalizado.

Ciertamente, existen críticas serias al enfoque de la Nueva Macroeconomía Clásica sobre la clarificación del mercado, el cual se sale del terreno realista para caer en el campo nominalista, mientras que las hipótesis sobre las expectativas racionales tienen que ser consistentes con el modelo económico que cargan los individuos en sus mentes.

\section{NUEVA ECONOMÍA POLÍTICA INSTITUCIONAL}

La Nueva Economía Política evita el holísmo de la economía ortodoxa, para apreciar los fenómenos sociales en las instituciones, tales como la cultura corporativa, etc., realizar análisis de las políticas mediante análisis institucional comparativo. La nueva economía política se enfoca al crecimiento económico prioritariamente y a la calidad de la gobernabilidad democrática. Los que promueven la aplicación de los principios de la Nueva Economía Política centrada en el libre mercado, son los primeros que abandonan sus posiciones en tiempos de crisis económicas y retornan a buscar la protección del Estado-nación para extraer los recursos financieros necesarios para sortear sus problemas y eliminar los riesgos a sus inversiones. Resulta esencial, por ejemplo, que el no respeto de las normas dictadas por la OIT pueda ser sancionado de modo que el trabajo no siga siendo una variable de ajuste sometida a los intereses financieros defendidos por las IFI y la OMC.

La nueva economía política se orienta a la consecución del crecimiento económico y la gobernabilidad democrática. No obstante, la aplicación por los gobiernos de los países en desarrollo, de una nueva economía política que hace un énfasis mayor en políticas económicas consistentes con el libre mercado y en la búsqueda de una gobernabilidad democrática, derivó en procesos regresivos de crecimiento económico y en crisis de gobernabilidad.

El paradigma de la Nueva Economía Institucional se interesa en las cualidades de coordinación de las instituciones, la coordinación está relacionada con el conjunto de instituciones capaces de producir expectativas que hacen posible a los individuos que no siguen los 
lineamientos de los planes centrales y que difieren en sus metas, para coordinar sus planes exitosamente.

En la nueva economía institucional, los aspectos políticos limitan los beneficios del comercio, como en las situaciones específicas de negociaciones asimétricas debido a que prevalecen intereses creados que originan conflictos distributivos. En los análisis de la Nueva Economía Institucional, término atribuido a Oliver Williamson, la calidad de las instituciones tiene un papel determinante en la pobreza, considerando que la ejecución de transacciones tiene un costo.

La Nueva Economía Institucional da origen al término gobernabilidad en referencia a las instituciones que la sociedad debe poseer a fin de monitorear las reglas del juego. La Nueva Economía Institucional deja en claro que las instituciones económicas, políticas y jurídicas son incompletas en cualquier sociedad y por lo tanto los costos de transacción no alcanzan los niveles deseados en el paradigma de la eficiencia. Las instituciones económicas más que el tipo de régimen político sustenta el crecimiento económico.

A partir de los fundamentos teórico-metodológicos de las relaciones entre el desarrollo económico y las instituciones jurídicas que establece la Nueva Economía Institucional, se superan las limitaciones del análisis del "movimiento del derecho y el desarrollo", y se establecen las bases para la construcción del Estado de Derecho promovedor del desarrollo económico.

La transformación de capital social en político explica la formación de las políticas públicas con el apoyo instrumental teórico metodológico de la nueva economía institucional, la teoría principal-agente, etc. y, por lo tanto, determinan la acumulación del capital social de los diversos actores y su inversión en áreas diferentes, dependiendo de su capacidad para identificar formas más eficientes de transformación de capital. El capital político se refiere a las actitudes y actividades que influencian al Estado "en la perspectiva privada, el capital político (instrumental) consiste en los recursos que un actor (...) puede disponer y usar para influenciar los procesos de formación de políticas y generar resultados de interés para el actor (...). En la perspectiva pública, el capital político se refiere a las variables estructurales del sistema político que influencian las posibilidades de los diversos actores políticos para acumular capital político instrumental, y que también terminan la efectividad de sus diversos tipos" (Birner y Wittmer, 2000).

\section{INSTITUCIONALIZACIÓN}

Las instituciones políticas deben promover el cambio institucional hacia formas más democráticas, sistemas de representación y participación de tal forma que maximice los intercambios entre los 
actores. Las sociedades más desarrolladas han generado sus propias condiciones para el cambio institucional que, según Prats (2002), "no puede ser sólo fruto de la voluntad humana como sigue pretendiendo el racionalismo instrumental constructivista, aunque como veremos ésta - y con ella los sentimientos y valoraciones éticas - juegan un rol importante".

La información estratégica que tienen los diferentes actores explica su comportamiento estratégico en la racionalidad del diseño de los arreglos institucionales. El diseño de las instituciones pragmáticas se hace en función de contratos deliberados que tienen como base la teoría de la información imperfecta y los costos de transacción. En los contratos que dan forma a las decisiones basadas en la elección racional, la aplicación de los términos no da a lugar a contratos que sean óptimos socialmente, mientras que el diseño de términos del contrato por el gobierno da lugar a opciones imperfectas. Las instituciones orgánicas son el resultado impredecible de la evolución gradual de la persecución de intereses individuales.

La crisis de gobernabilidad resulta cuando los conflictos entre los diversos actores estratégicos tradicionales y emergentes cuestionan el equilibrio institucional del sistema sociopolítico debido principalmente a un deficiente sistema de institucionalización de reglas y procedimientos. El origen de las crisis de gobernabilidad puede proceder, siguiendo a Prats (2001), de la incapacidad de las reglas y procedimientos para resolver problemas de interacción o de acción colectiva, de una institucionalización de reglas y procedimientos débiles o inadecuados, de la emergencia de nuevos actores estratégicos y del cambio estratégico de actores poderosos. El sistema sociopolítico delimita el comportamiento de los diversos actores que establecen sus expectativas y dirimen sus conflictos de intereses en un marco de estructura institucional.

La discriminación y la exclusión social son dos fenómenos que demeritan los sistemas democráticos e impiden los procesos de institucionalización democrática.

Bajos costos de transacción en la esfera económica y política que varían dependiendo de los sistemas institucionales que prevalecen en las sociedades, inciden en incrementos del crecimiento económico y por tanto en la reducción de los niveles de pobreza. Más bajos costos de transacción en las esferas económicas y políticas contribuyen al crecimiento y, por lo tanto, afectan los niveles de ingreso y por tanto de pobreza. Los bajos costos de transacción son esenciales para el crecimiento económico los cuales varían en los diferentes sistemas de instituciones que existen en las sociedades. La estructura de los costos de transacción varía en los mercados económicos y políticos que gravitan en cualquier sociedad. Las imperfecciones del mercado derivan en altos 
costos de transacción que limitan los incentivos de las estructuras de las economías y causan un desempeño económico pobre.

\section{TRANSFORMACIONES INSTITUCIONALES DEL ESTADO -NACIÓN}

Los analistas y teóricos de los procesos de globalización se equivocan cuando sentencian la muerte prematura del Estado nación, cuando en realidad se aprecia fuertes procesos de transformación institucional de sus funciones en la economía política mundial. El Estado sigue siendo un actor de la globalidad y de la economía política mundial importante, cuyas funciones son relevantes para la promoción y el control de la estructura hegemónica del sistema capitalista imperial. La estructura espacial de las diferentes unidades geográficas se delimita territorialmente en función de sus fronteras físicas y geográficas y definen las interrelaciones entre las diferentes entidades.

El sistema capitalista transnacional tiene contradicciones internas que hacen que el Estado Neoliberal atraviese por una crisis de gobernabilidad y legitimidad, debido que los procesos de globalización impulsados debilitan la integración económica interna, se pierde la capacidad para armonizar los intereses sociales conflictivos y, por tanto, para mantener la cohesión social de los estados nacionales. Sin embargo, se está demostrando que el libre comercio bajo, el esquema de la globalización económica, no mejora necesariamente las condiciones de competitividad en aquellos países donde no existen, regularmente los países pobres.

El Estado, el mercado y la comunidad son mecanismos de coordinación y gobernabilidad imperfectos, que presentan cada uno diferentes ventajas y desventajas, pero que se complementan.

La reforma del Estado modifica su capacidad reguladora y su papel de protección y asistencia a la comunidad. La reforma del Estado basada en el modelo racional normativo weberiano se caracteriza por la racionalización legalista del Estado que fortalece la administración burocrática de estructuras verticales y una cultura patrimonialista y clientelar, se realizó desde los años cincuenta y hasta los ochenta.

Pero este viejo modelo de gestión pública burocrática basada en una racionalidad normativa ha cedido paso a un modelo de gestión orientado por una racionalidad tecnocrática. Los procesos de modernización implican el cálculo y control de los procesos sociales y naturales que corresponden al desarrollo de la racionalidad instrumental, la cual se contrapone al concepto de racionalidad normativa que se corresponde con la modernidad orientada a la autonomía moral y a la autodeterminación política. 
La reforma administrativa de los setenta se orientó a la búsqueda de la racionalidad instrumental y la neutralidad política. En los ochenta se transita de la administración a la gerencia pública en la búsqueda de las organizaciones gubernamentales más eficientes y eficaces mediante el uso de racionalidades instrumentales. Se desarrolla el concepto de políticas públicas orientadas por el Consenso de Washington y se profundiza en los procesos de formulación e implementación. El crecimiento económico y el desarrollo de un país se explican por sus instituciones.

Mediante un nuevo diseño institucional sustentado en cambios constitucionales, se amplía la distribución del poder a las organizaciones sociales y privadas. Actualmente, la reforma del Estado enfatiza las reformas institucionales que fortalecen la gobernabilidad con base en un sistema democrático y de libre mercado (Prats, 1998). Las reformas institucionales de largo alcance, también llamadas reformas de segunda generación, pueden orientarse para alcanzar una mayor eficiencia económica y mejores niveles de desarrollo y equidad social.

Así, el perfil de las burocracias latinoamericanas se aleja del modelo racional de burocracia de Weber para ajustarse a las necesidades del modelo de Estado social democrático. Bajo el supuesto del "secuenciamiento", para entrar a la reforma de la nueva gerencia que promueve una mayor flexibilidad en el empleo público, era necesario haber cubierto completamente la etapa de los servicios públicos que implicó el servicio civil en los administradores de carrera. La reforma del aparato burocrático administrativo del Estado está orientada en el nuevo gerencialismo, procesos de democratización y hacia los consumidores que en mercados competitivos realizan elecciones racionales, lo que termina reduciendo al ciudadano en un consumidor.

Contrariamente a la retórica de los empresarios y la clase capitalista transnacional, el Estado seguirá desempeñando un rol importante que requieren el fortalecimiento de sus funciones de regulación, cuya finalidad es eliminar los riesgos que pueden atentar contra sus inversiones y garantizar la reproducción y el acrecentamiento de sus capitales. El Estado sigue siendo un actor de la globalidad y de la economía política mundial importante, cuyas funciones son relevantes para la promoción y el control de la estructura hegemónica del sistema capitalista imperial. La regulación mundial no puede ser definida únicamente en términos institucionales: las cuestiones de derecho tienen su importancia. Es necesario que las Instituciones Financieras Internacionales se sometan al derecho internacional, especialmente a los protocolos y a los acuerdos que han suscripto la mayoría de los Estados miembros. 


\section{REFERENCIAS}

AMÍN, Samir. Imperialismo y globalización. 2001. Disponible en: http:/ /www.rcci.net/globalización/2001/fg175.htm

APPELBAUM, Richard; HENDERSON, Jeffrey. "The hinge of history: Turbulence and transformation in the world economy". Competition \& change, Vol. 1, number 1, 1995.

BIRCHFIELD, Vicki. "Contesting the hegemony of market ideology: Gramsci's 'good sense' and Polanyi's 'double movement". Review of International Political Economy 6:1 Spring 1999: 27-54.

BIRNER, Regina; WITTMER, Heidi. "Converting social capital into political capital. How do local communities gain political influence? A theorethical approach and empirical evidence from Thailand and Colombia", Paper submitted to the $8^{\text {th }}$ Biennal Conference of the International Association for the Study of Common Property (IASCP), 2000.

BURGOS SILVA, Germán. "Estado de Derecho y desarrollo económico: aportes y limitaciones de los análisis neinstitucionales", Revista Instituciones y Desarrollo, $N^{\circ} 12-13$. Institut Internacional de Governabilitat de Catalunya, Barcelona, páginas 193-221, 2002.

COASE, R. "The nature of the firm". Económica, 4, 386-401, 1937.

COLEMAN, James. "Social capital in the creation of human capital". American Journal of Sociology, Supplement, Vol. 95, pp. 95-120. The University of Chicago, Chicago, 1988.

DIETERERICH STEFFAN, Heinz (2002)."Libertad de comercio, apología y oportunismo", El Universal, Sábado 03 de agosto de 2002.

ESTEFANÍA, Joaquín. "La enfermedad moral del capitalismo", Granito de arena. Argentina, 2002.

GIDDENS, A. The constitution of society. Los Angeles: University of California Press, 1984.

GILBERT, Evan; MICHIE, Jonathan. ""New classical macroeconomic theory and fiscal rules: some methodological problems", Contributions to Political Economy, 16, 1997.

HABERMAS, J. Faktizät und geltung -Beiträge zur Diskurstheorie des Reshcts und des demokratischen rechtsstaats, Darmstadt:Wissenschaftliche Buchgesellschaft, 1992.

HERMALIN, E. Benjamin. "Economics \& corporate culture", Draft. Cornell University and University of California, Berkeley, 1999. 
LAWRENCE, Robert Z. Regionalismo, multilaterismo e integración profunda. Washington, DC: Brookings, 1996.

NORTH, D.D. Institutions, Institutional Change and Economic Performance, Cambridge, Cambridge University Press, 1991.

OLSON, Mancur. "Dictatorship, Democracy and Development", en American Political Science Review, vol. 87, número 3, septiembre, 1993.

PRATS, Joan. Instituciones y desarrollo en América Latina ¿Un rol para la ética? Instituto Internacional de Gobernabilidad. 17 de septiembre de 2002.

. "Gobernabilidad democrática para el desarrollo humano. Marco conceptual y analítico", Instituciones y Desarrollo, No. 10, Octubre 2001. Barcelona, España. Disponible en: http://www.iigov.org/revista/ re10/re10_04.htm.

PARSONS, T. Structure and process in modern societies. Chicago: Chicago Free Press, 1960.

POLANYI K.; ARENSBERG C.; PEARSON H, (edits.), (1975). Les systémes économiques dans l'économie, Paris, Librairie Larousse, 1975. (1 ${ }^{\mathrm{a}} \mathrm{Ed}$. en 1957 con el título: Trade and Market in the Early empires).

SALDOMANDO, Algel. "La cooperación en gobernabilidad", Instituto Internacional de Gobernabilidad, 2002. Disponible en: http:// www.iigov.org/documentoa/tema1/docu0098.htm

SHEPSLE, Kenneth; WEINGAST, Barry. Positive Theories of Congressional Institutions Legislative Studies Quarterly, Vol. 19, no. 2. pp.149-179, 1994.

SIMON, Herbert A. "A behavioral model of rational choice", Quarterly Journal of Economics, 69 (February 1955): 99-118, 1955.

STREETER, Prieto J. Materiales de trabajo sobre el orden público económico. Mimeo, Faculktad de Derecho, Universidad de Chile, 1985.

TOMLINSON, John. Globalization and culture. Polity Press: Cambridge, 1999.

TOWNLEY, Barbara. The role of competing rationalities in institutional change. Academy of Management Journal, Vol. 45, No. 1, 163-169, 2002 .

WEIMER, David L. Institutional design. Boston: Kluwer, 1995. 